\title{
Endogenous Klebsiella endophthalmitis
}

\begin{abstract}
Purpose To report 4 cases of endogenous Klebsiella endophthalmitis. This disease is a rare but devastating complication of Klebsiella sepsis. Familiarity with its varied clinical presentations would aid in early diagnosis and institution of appropriate therapy.

Methods We report 5 eyes of 4 patients with endogenous Klebsiella endophthalmitis from December 1995 to September 1996 and review the literature regarding previously successfully treated cases.
\end{abstract}

Results The mean age of the patients was 67.5 years (range 37-85 years). One patient had bilateral involvement. At presentation, 3 eyes had a visual acuity of no perception of light (NPL) and the 1 patient with bilateral involvement had an acuity of counting fingers in one eye and 20/40 in the other. The primary source of sepsis was the pulmonary system in 2 patients, the hepatobiliary system in 1 patient and the urinary tract in 1 patient. One patient had coexisting diabetes mellitus. Two patients had a pupillary hypopyon. Local and systemic treatment with an aminoglycoside and cephalosporin was initiated. Despite treatment, 2 eyes remained NPL. One eye developed a globe perforation and was eviscerated. The patient with bilateral involvement was treated within $8 \mathrm{~h}$ and recovered fully with a final visual acuity of $20 / 20$ in both eyes.

Conclusion It is important to have a high index of suspicion in patients with septicaemia presenting with intraocular inflammation, especially in diabetics with suppurative liver disease, urinary tract infection or pulmonary infection. As the visual prognosis for patients with Klebsiella endophthalmitis is generally poor, early diagnosis and treatment with intravenous and intravitreal antibiotics may improve the visual outcome.

Key words Bacterial endophthalmitis, Diabetes mellitus, Klebsiella pneumoniae, Metastatic endophthalmitis, Ocular infection

Bacterial endophthalmitis is an uncommon but devastating disease, which often leaves the patient with significant visual impairment. Bacterial endophthalmitis may arise as a complication of ocular surgery, penetrating trauma or systemic infection. Endogenous Klebsiella endophthalmitis is a rare complication of Klebsiella sepsis and has been reported in the literature only occasionally. ${ }^{1-3}$ This disease has a poor visual prognosis in spite of early treatment with intraocular antibiotics, with or without vitrectomy. Salvageable vision is limited to those few patients who received early treatment. $^{4-6}$

We report 5 eyes of 4 patients with endogenous Klebsiella endophthalmitis who presented to our hospital from December 1995 to September 1996, to highlight the clinical presentation, treatment and visual outcome of this ocular condition. We also review the literature regarding previously successfully treated cases.

\section{Case reports}

\section{Case 1}

An 85-year-old man was admitted to the medical department with complaints of cough, fever and breathlessness for 4 days.

Examination revealed fine crepitations over the lower lung fields. The next day, the patient developed decreased vision in the left eye associated with redness and pain. The patient was given topical chloramphenicol eye drops by the attending physician but his vision continued to deteriorate and he was referred to the ophthalmology department on the third day of ocular symptoms.

Examination revealed no perception of light in the left eye. The left pupil was non-reactive to light. There was left eyelid oedema, conjunctival injection, chemosis and corneal oedema. The anterior chamber showed severe cellular reaction with a pupillary hypopyon. Significant vitritis was present causing poor visualisation of the posterior pole. B-scan ultrasonography revealed diffuse vitreous debris with a posterior vitreous detachment. The right pseudophakic eye was normal.

The leucocyte count was $4800 / \mu l$ with $93 \%$ neutrophils. A chest roentgenogram showed bilateral pulmonary infiltrates over the lower lung fields with slight pleural effusion. Abdominal ultrasonograms of the liver and kidneys were normal.

\author{
L.P.-K. Ang \\ Singapore National Eye \\ Center \\ 11, Third Hospital Avenue \\ Singapore 168751 \\ H.-M. Lee \\ K.-G. Au Eong \\ E.-Y. Yap \\ A.T.-H. Lim \\ Department of \\ Ophthalmology \\ Tan Tock Seng Hospital \\ Moulmein Road \\ Singapore 308433 \\ K.-G. Au Eong \\ A.T.-H. Lim \\ Singapore Eye Research \\ Institute \\ c/o Singapore National Eye \\ Centre \\ 11 Third Hospital Avenue \\ Singapore 168751
}

Dr Leonard Pek-Kiang Ang Singapore National Eye Centre

11, Third Hospital Avenue Singapore 168751

Tel: +65 2277255

Fax: +652277290

e-mail: leopk@pacific.net.sg

Received: 7 January 2000 Accepted in revised form: 8 June 200 
Vitreous aspiration of the left eye for culture was performed. Intravitreal injections of $100 \mu \mathrm{g}$ gentamicin and $2.25 \mathrm{mg}$ cefazolin were given, as well as subconjunctival injections of $20 \mathrm{mg}$ gentamicin and $100 \mathrm{mg}$ cefazolin. Hourly topical gentamicin $(18 \mathrm{mg} / \mathrm{ml})$ and cefazolin $(50 \mathrm{mg} / \mathrm{ml})$ eye drops were started. The patient was already on intravenous ceftazidime and erythromycin for treatment of bronchopneumonia. Klebsiella pneumoniae was cultured from the blood, sputum and vitreous. The organism was sensitive to cephalosporins and aminoglycosides but resistant to penicillins. The antibiotics were changed to intravenous ceftriaxone $2 \mathrm{~g}$ twice daily and gentamicin $80 \mathrm{mg}$ twice daily.

The intraocular inflammation persisted after the first week and a repeat vitreous biopsy and intravitreal injection of cefazolin and gentamicin was performed. The ocular and respiratory infection responded after 3 weeks of antibiotic therapy. The visual acuity of the left eye did not improve and remained as NPL.

\section{Case 2}

A 67-year-old woman was admitted for complaints of abdominal pain, jaundice, tea-coloured urine and fever for 2 days. Her right hypochondrium was tender and guarded. Laboratory investigations revealed an elevated leucocyte count of $28700 / \mu$ l with $93 \%$ neutrophils, elevated total bilirubin and liver enzymes, and markedly elevated serum alkaline phosphatase. An abdominal ultrasonogram revealed a $9 \mathrm{~cm} \times 7 \mathrm{~cm} \times 5 \mathrm{~cm}$ right hepatic lobe abscess. The patient underwent a laparotomy and drainage of the liver abscess on the second day.

Six days after admission, the patient developed decreased vision in the right eye associated with redness. This was initially treated with chloramphenicol eye drops and tetracycline ointment by the attending physician. Her eye condition worsened and she was referred to the ophthalmology department 5 days later. The right eye had a visual acuity of NPL, and there was conjunctival injection, chemosis and corneal oedema. There was marked anterior chamber inflammation. The right pupil was non-reactive to light. There was vitritis and the posterior pole could not be visualised because of hazy media. Her left eye was normal.

A right vitreous biopsy was performed and sent for culture. Intravitreal injections of $100 \mu \mathrm{g}$ gentamicin and $2.25 \mathrm{mg}$ cefazolin, and subconjunctival injections of $20 \mathrm{mg}$ gentamicin and $125 \mathrm{mg}$ cefazolin were given. Intravenous ceftriaxone $2 \mathrm{~g}$ daily and gentamicin $80 \mathrm{mg}$ 8-hourly and topical hourly treatment with gentamicin $(18 \mathrm{mg} / \mathrm{ml})$ and cefazolin $(50 \mathrm{mg} / \mathrm{ml})$ eye drops were started. Cultures of the blood, urine and abscess fluid grew Klebsiella pneumoniae. No bacterium was isolated from the vitreous culture. The organism was sensitive to cephalosporins and aminoglycosides, but was resistant to penicillins.
The septicaemia and ocular infection improved gradually with treatment. Intravenous antibiotics were continued for 3 weeks and converted to oral ciprofloxacin $500 \mathrm{mg}$ twice daily. The patient was discharged after 1 month in hospital. The visual acuity of the affected eye, however, remained NPL.

\section{Case 3}

An 81-year-old woman with a history of diabetes mellitus and ischaemic heart disease on oral medication was seen in the emergency department for increasing drowsiness and left eye redness, pain and swelling for 3 days. The patient was afebrile, drowsy and lethargic. Visual acuity could not be ascertained as she was not responsive. Ophthalmic evaluation of the left eye revealed left proptosis and eyelid oedema, with conjunctival injection, chemosis and corneal oedema. There was a left relative afferent pupillary defect and eye movements were significantly reduced. Moderate anterior chamber cellular reaction with vitritis was present and the fundus could not be visualised. The right eye showed no evidence of inflammation.

B-scan ultrasonography showed dense vitreal debris in the left eye. The leucocyte count was elevated to $12800 / \mu$ l with $76 \%$ neutrophils, and there was significant pyuria. A computed tomogram of the orbits revealed left proptosis and orbital cellulitis, mostly in the preseptal area.

A left vitreous tap was performed and showed purulent aspirate. Intravitreal injections of $100 \mu \mathrm{g}$ gentamicin and $1 \mathrm{mg}$ vancomycin were given. The patient was started on hourly gentamicin $(18 \mathrm{mg} / \mathrm{ml})$ and cefazolin $(50 \mathrm{mg} / \mathrm{ml})$ eye drops and intravenous gentamicin $40 \mathrm{mg}$ 8-hourly and ceftriaxone $1 \mathrm{~g}$ twice daily. A repeat vitreal tap and intravitreal injections of $100 \mu \mathrm{g}$ gentamicin and $2.25 \mathrm{mg}$ cefazolin were performed on the fourth and seventh hospital days. All vitreous taps obtained purulent aspirates. Cultures from the vitreous tap, blood and urine were all positive for Klebsiella pneumoniae. The organism was resistant to penicillins and first- and second-generation cephalosporins. It was sensitive to third-generation cephalosporins and aminoglycosides.

Despite antibiotic therapy the ocular infection did not improve. On hospital day 10, the patient developed a globe perforation in the left eye and subsequently underwent evisceration of the eye. The patient was on 3 weeks of intravenous antibiotics and converted to oral ciprofloxacin $500 \mathrm{mg}$ twice daily. The septicaemia eventually resolved and she was discharged after 1 month in hospital.

\section{Case 4}

A 37-year-old man presented with fever, chills, rigors and cough for 5 days, associated with bilateral pleuritic chest pain with reduced breath sounds and crepitations over the lower lung fields. Sputum cultures were taken and the patient was started empirically with intravenous 
crystalline penicillin and ceftriaxone. The next day, the patient developed acute onset of visual loss and redness in the left eye. He was referred to our department immediately and was seen within $8 \mathrm{~h}$ of onset of visual symptoms. The patient had a visual acuity of $6 / 12$ in the right eye and counting fingers at 6 inches $(15 \mathrm{~cm})$ in the left eye. Slit-lamp examination showed bilateral mild conjunctival injection and clear corneas. Anterior chamber cells of grade $3+$ were present in the right eye and of grade $4+$ in the left eye. A pupillary hypopyon was noted in the left eye. The left pupil reacted sluggishly to light. Vitritis was present bilaterally. The left fundus could not be visualised because of hazy media. A flame-shaped haemorrhage and a Roth spot were noted in the right fundus.

Laboratory investigations revealed an elevated leucocyte count and pyuria. Pulmonary infiltrates over both lower lung fields were noted on the chest roentgenogram. Bilateral vitreous biopsies were taken for culture and sensitivity, and intravitreal injections of $100 \mu \mathrm{g}$ gentamicin and $1 \mathrm{mg}$ vancomycin were given bilaterally. Topical gentamicin $(18 \mathrm{mg} / \mathrm{ml})$ and cefazolin $(50 \mathrm{mg} / \mathrm{ml})$ eye drops were started. Intravenous antibiotics were changed to ceftriaxone $2 \mathrm{~g}$ daily and gentamicin $60 \mathrm{mg}$ 8-hourly. Cultures from the blood and sputum were positive for Klebsiella pneumoniae. No organism was isolated from the urine and vitreal cultures. The organism was sensitive to aminoglycosides and cephalosporins, but was resistant to penicillins.

The patient's vision deteriorated to $6 / 24$ in the right eye and counting fingers closely in the left, and a repeat vitreous biopsy and intravitreal injection of $100 \mu \mathrm{g}$ gentamicin was performed on the fourth hospital day. Vitreal fluid cultures remained negative. After 10 days of treatment, the patient's ocular and systemic infection gradually improved and his visual acuity returned to 6/6 in the right eye and $6 / 15$ in the left. The patient was given 2 weeks of intravenous antibiotic therapy and was converted to oral cefuroxime. He was discharged with after 19 days of hospitalisation. Two weeks later there was complete recovery from his illness and his left visual acuity returned to $6 / 6$.

\section{Discussion}

Klebsiella pneumoniae is a highly virulent Gram-negative bacterium which causes devastating endophthalmitis. Endogenous Klebsiella endophthalmitis is a very rare disorder and its diagnosis and optimal means of treatment are addressed infrequently in the literature. ${ }^{5-11}$
It is associated with a very poor visual prognosis despite intensive antibiotic treatment, with nearly all cases having a visual outcome of hand motion or worse. ${ }^{6-16}$ It is especially rare in Western countries. ${ }^{4,7,12-14}$ The majority of cases reported occurred among Orientals, possibly due to the fact that the incidence of Klebsiella in pyogenic liver abscess is significantly higher among Orientals. ${ }^{5-11,15,16}$

The characteristics, microbiology and visual outcome of the patients in our series are summarised in Table 1. The authors found that patients with Klebsiella endophthalmitis may characteristically present with an unusual purulent exudate at the pupillary aperture, hence the term pupillary hypopyon. This was found in 2 of our patients and in 2 previous reports. ${ }^{6,15}$ This is probably due to the fulminant spillover of the purulent contents behind the iris-lens diaphragm, with the exudates settling on the lens due to the effect of gravity, as most of these patients were ill and bedridden. This clinical sign might therefore be useful in the provisional diagnosis during the initial presentation of these patients, thereby allowing a more discriminative antibiotic selection in the treatment of this ocular emergency.

The diagnosis was confirmed by isolation of Klebsiella pneumoniae from the blood and non-ocular fluids in all patients. The organism was cultured from the vitreous fluid in two patients. In other studies, positive cultures from ocular fluids were also not always obtainable, and the diagnosis was made from clinical evidence of septicaemia and endophthalmitis, with culture positive cultures obtained from the blood and various nonocular sites. ${ }^{2,6,9,16}$

Good vision has been achieved in only 3 cases previously reported. ${ }^{4-6}$ One patient in our series with bilateral involvement was successfully treated, making this the fourth reported case of a successful outcome. We reviewed the clinical history of these 4 successful cases to see whether there were any clinical features which might be predictive of a favourable outcome, as well as to compare the treatment instituted for these patients. The findings are summarised in Table 2 . The onset of endophthalmitis ranged from 4 to 20 days after the onset of sepsis. Several similarities exist. All these patients were already on treatment for Klebsiella sepsis prior to developing ocular symptoms of endophthalmitis. These patients were referred to the ophthalmologist early, thereby allowing prompt diagnosis and institution of treatment for the condition. All 4 patients were seen and treated within 2 days of onset of symptoms. All eyes

Table 1. Clinical summary of endogenous Klebsiella endophthalmitis

\begin{tabular}{|c|c|c|c|c|c|c|c|c|}
\hline $\begin{array}{c}\text { Patient } \\
\text { no. }\end{array}$ & $\begin{array}{c}\text { Age } \\
\text { (years)/ } \\
\text { Sex }\end{array}$ & $\begin{array}{l}\text { Diabetes } \\
\text { mellitus }\end{array}$ & $\begin{array}{c}\text { Duration of } \\
\text { symptoms } \\
\text { before diagnosis }\end{array}$ & $\begin{array}{c}\text { Source of } \\
\text { sepsis }\end{array}$ & $\begin{array}{l}\text { Klebsiella } \\
\text { cultured }\end{array}$ & $\begin{array}{c}\text { Eye } \\
\text { affected }\end{array}$ & $\begin{array}{c}\text { Visual } \\
\text { acuity at } \\
\text { presentation }\end{array}$ & $\begin{array}{c}\text { Final visual } \\
\text { outcome }\end{array}$ \\
\hline 1 & $85 / \mathrm{M}$ & No & 3 days & Lung & Blood, sputum, vitreous & Left & $\overline{N P L}$ & NPL \\
\hline 2 & $67 / F$ & No & 5 days & Liver & Blood, liver, urine & Right & NPL & NPL \\
\hline 3 & $81 / \mathrm{F}$ & Yes & 3 days & Urinary tract & Blkood, urine, vitreouis & Left & NPL & Eviscerated \\
\hline \multirow[t]{2}{*}{4} & $37 / \mathrm{M}$ & No & 8 hours & Lung & Blood, sputum & Right & $6 / 12$ & $6 / 6$ \\
\hline & & & & & & Left & $\mathrm{CF}$ & $6 / 6$ \\
\hline
\end{tabular}




\begin{tabular}{|c|c|c|c|c|c|c|c|c|c|c|}
\hline \multirow[b]{2}{*}{ Reference } & \multirow{2}{*}{$\begin{array}{l}\text { Age } \\
\text { (years)/ } \\
\text { Sex }\end{array}$} & \multirow{2}{*}{$\begin{array}{l}\text { Diabetes } \\
\text { mellitus }\end{array}$} & \multirow{2}{*}{$\begin{array}{l}\text { Right/ } \\
\text { left eye }\end{array}$} & \multirow{2}{*}{$\begin{array}{l}\text { Duration } \\
\text { from onset } \\
\text { of sepsis to } \\
\text { development }\end{array}$} & \multirow{2}{*}{$\begin{array}{l}\text { Duration } \\
\text { of ocular } \\
\text { symptoms } \\
\text { before } \\
\text { diagnosis }\end{array}$} & \multirow{2}{*}{$\begin{array}{l}\text { Source } \\
\text { of sepsis }\end{array}$} & \multirow{2}{*}{$\begin{array}{l}\text { Visual } \\
\text { acuity at } \\
\text { presentation }\end{array}$} & \multirow{2}{*}{$\begin{array}{l}\text { Final } \\
\text { visual } \\
\text { outcome }\end{array}$} & \multicolumn{2}{|c|}{ Treatment } \\
\hline & & & & & & & & & Ocular & Systemic \\
\hline $\begin{array}{l}\text { Sipperley } \\
\text { and Shore }\end{array}$ & $57 / F$ & Yes & Right & 4 days & $\begin{array}{l}\text { Within } 2 \\
\text { days }\end{array}$ & $\begin{array}{l}\text { Liver } \\
\text { abscess }\end{array}$ & $\mathrm{HM}$ & $6 / 9$ & $\begin{array}{l}\text { Vitrectomy; } \\
\text { intravitreal } \\
\text { gentamicin } \\
0.1 \mathrm{mg} \text {; sub- } \\
\text { conjunctival } \\
\text { gentamicin } \\
40 \mathrm{mg}\end{array}$ & $\begin{array}{l}\text { Intravenous } \\
\text { gentamicine } \\
\text { and } \\
\text { clindamycin }\end{array}$ \\
\hline Wang et al. ${ }^{5}$ & $57 / \mathrm{M}$ & No & Left & 20 days & $\begin{array}{l}\text { Within } \\
1-2 \text { days }\end{array}$ & $\begin{array}{l}\text { Liver } \\
\text { abscess }\end{array}$ & $\mathrm{CF}$ at $30 \mathrm{~cm}$ & $6 / 7.5$ & $\begin{array}{l}\text { Intravitreal } \\
\text { cefazolin } \\
2.25 \mathrm{mg} \text { and } \\
\text { gentamicin } \\
0.2 \mathrm{mg} \text {; sub- } \\
\text { conjunctival } \\
\text { gentamicin } \\
16 \mathrm{mg} \text { and } \\
\text { dexametha- } \\
\text { sone } 2 \mathrm{mg}\end{array}$ & $\begin{array}{l}\text { Intravenous } \\
\text { gentamicin } \\
\text { and } \\
\text { cefatriaxone }\end{array}$ \\
\hline Chee et al. ${ }^{6}$ & $81 / \mathrm{F}$ & Yes & Bilateral & 9 days & $\begin{array}{l}\text { Within } \\
24 \text { hours }\end{array}$ & $\begin{array}{l}\text { Liver } \\
\text { abscess }\end{array}$ & $\begin{array}{l}\text { OD, CF } 3 \text { ft; } \\
\text { OS, CF } \\
\text { closely }\end{array}$ & $\begin{array}{l}\text { OD, 6/6; } \\
\text { OS, 6/36 }\end{array}$ & $\begin{array}{l}\text { Intravitreal } \\
\text { cefazolin } \\
2.25 \mathrm{mg} \text { and } \\
\text { gentamicin } \\
0.1 \mathrm{mg} \text {; sub- } \\
\text { conjunctival } \\
\text { gentamicin } \\
\text { and cefazolin; } \\
\text { topical } \\
\text { gentamicin } \\
\text { and cefazolin } \\
\text { eyedrops }\end{array}$ & $\begin{array}{l}\text { Intravenous } \\
\text { gentamicin } \\
\text { and } \\
\text { ceftriaxone }\end{array}$ \\
\hline Our series & $37 / \mathrm{M}$ & No & Bilateral & 6 days & 8 hours & Lung & $\begin{array}{l}\text { OD, } 6 / 12 ; \\
\text { OS, CF at } \\
15 \mathrm{~cm}\end{array}$ & $\begin{array}{l}\text { OD, 6/6; } \\
\text { OS, } 6 / 6\end{array}$ & $\begin{array}{l}\text { Intravitreal } \\
\text { vancomycin } \\
1 \mathrm{mg} \text { and } \\
\text { gentamicin } \\
0.1 \mathrm{mg} ; \\
\text { topical } \\
\text { gentamicin } \\
\text { and cefazolin } \\
\text { eyedrops }\end{array}$ & $\begin{array}{l}\text { Intravenous } \\
\text { gentamicin } \\
\text { and } \\
\text { ceftriaxone }\end{array}$ \\
\hline
\end{tabular}

were treated with intravitreal $100 \mu \mathrm{g}$ gentamicin as well as intravenous gentamicin, which the Klebsiella organisms isolated from these patients were sensitive to. Only one eye underwent vitrectomy. The visual acuity at the time of diagnosis was counting fingers or worse, except for the less affected eye of the patient in our series with bilateral involvement which had 6/12 vision. Anterior chamber and vitreous inflammation was already significant despite the patient being seen within 2 days of onset of symptoms. There were no clinical features which could be identified as predictive of a favourable outcome. The rapidity of deterioration of vision demonstrates the virulence of the organism. A common factor in these cases was the early diagnosis and treatment, which was probably the major contributing factor towards a favourable visual outcome.

Early diagnosis and treatment is therefore important in the management of this condition. Much of the delay in treatment can be attributed to a failure to recognise the condition early. The first 2 cases in our series were initially misdiagnosed by the physician. In a 10-year retrospective study by Okada et al., ${ }^{1}$ it was found that only $50 \%$ of patients were correctly diagnosed by physicians at presentation (half of whom were ophthalmologists), with a delay in diagnosis of 4 days or more in $29 \%$ of patients.

Early diagnosis is particularly crucial when dealing with Gram-negative organisms, such as Klebsiella pneumoniae, which are associated with more severe disease. Physicians and ophthalmologists must therefore have a high index of suspicion when diabetic patients with suppurative liver disease, urinary tract infection or pneumonia develop ocular symptoms. Of the 68 cases reported in the literature previously, $71 \%$ of patients with endogenous Klebsiella endophthalmitis had suppurative liver disease, $18 \%$ had urinary tract infection and $13 \%$ had pneumonia. ${ }^{4-16}$ Diabetes mellitus has been found to be a significant predisposing factor for Klebsiella sepsis, 
with $72 \%$ of the patients having the disease. ${ }^{4-16}$ In our series, the source of infection was the pulmonary system in 2 patients, hepatobiliary system in 1 patient and the urinary tract in 1 patient. A history of diabetes mellitus was present in 1 patient.

We advocate the use of intravenous and intravitreal antibiotics in the treatment of this condition. Intravenous antibiotics are crucial in the treatment of the ocular infection as well as the original source of infection, thereby preventing further embolisation of organisms to the eye. ${ }^{1-3,17-20}$ Intravitreal antibiotics overcome the problem of inadequate penetration of antibiotics into the vitreous after periocular or systemic therapy. ${ }^{1-3,17-20}$ Greenwald et al. ${ }^{2}$ proposed that prompt and intensive intravenous antibiotic administration was the most critical element in the treatment of metastatic bacterial endophthalmitis. The antibiotic regimen is modified, if necessary, on the basis of culture and in vitro sensitivity results. Antibiotic treatment should be continued for at least 2-3 weeks or longer until it is certain that the systemic infection has been eradicated. ${ }^{1,2,17}$

In the successful cases in the literature, the patients received intravitreal $100 \mu \mathrm{g}$ gentamicin, and most were given intravenous gentamicin and a third-generation cephalosporin (ceftriaxone). ${ }^{4-6}$ In our series, all the patients were treated initially with combination antibiotic therapy comprising an aminoglycoside and a cephalosporin or vancomycin for broad spectrum antibiotic cover. The Klebsiella pneumoniae cultured from our patients were sensitive to gentamicin and cephalosporins (cefazolin and ceftriaxone). These antibiotics were administered as topical eyedrops, subconjunctival and intravitreal injections and intravenous injections. Aminoglycosides have been considered the drugs of choice for Gram-negative infections, such as Klebsiella, and they continue to provide excellent Gram-negative coverage. ${ }^{3,21}$ However, one must also be alert to the potential retinotoxic effects of aminoglycosides. ${ }^{22}$

The role of vitrectomy in endogenous endophthalmitis is controversial..$^{1-3,17-20}$ For postoperative bacterial endophthalmitis, the Endophthalmitis Vitrectomy Study ${ }^{23}$ showed an improvement in visual outcome of patients with perception of light or worse vision who underwent vitrectomy. However, for metastatic bacterial endophthalmitis there is no conclusive evidence to show that vitrectomy would improve visual prognosis. Some studies ${ }^{1,3,11,17,18}$ have shown that vitrectomy early in the course of disease may contribute to improved visual outcome, while others ${ }^{2,19,20}$ have shown no significant difference in visual outcome between patients treated conservatively and those who had vitrectomy performed. The benefits of vitrectomy have to be weighed against its risks, as patients are septicaemic and often severely ill at the time of diagnosis. In our study, none of the patients underwent vitrectomy because they were critically ill at the time of presentation and were unfit for any surgical procedure.
This paper highlights the fact that despite the dismal visual prognosis of Klebsiella endophthalmitis in the majority of patients, prompt diagnosis and treatment can preserve useful vision in some patients. Treatment in the form of intravitreal and intravenous antibiotics is advocated. Vitrectomy is often not possible in view of the poor physical state of these patients at the time of diagnosis. It is therefore important for physicians and ophthalmologists to be alert to the possibility of Klebsiella endophthalmitis in patients with Klebsiella sepsis, particularly in diabetics with hepatobiliary sepsis, urinary tract infection or pulmonary abscess, presenting with intraocular inflammation, as early diagnosis and treatment can improve the visual outcome.

\section{References}

1. Okada AA, Johnson RP, Liles WC, D'Amica DJ, Baker AS. Endogenous bacterial endophthalmitis: report of a ten-year retrospective study. Ophthalmology 1994;101:832-8.

2. Greenwald MJ, Wohl LG, Sell CH. Metastatic bacterial endophthalmitis: a contemporary reappraisal. Surv Ophthalmol 1986;31:81-101.

3. Irvine DW, Flynn HW Jr, Miller D, Pflugfelder SC. Endophthalmitis caused by gram-negative organisms. Arch Ophthalmol 1992;110:1450-4.

4. Sipperley JO, Shore JW. Septic retinal cyst in endogenous Klebsiella endophthalmitis [letter]. Am J Ophthalmol 1982;94:124-5.

5. Wang FD, Wang LS, Liu YC, Liu CY, Wong WW. Successful treatment of metastatic endophthalmitis: case reports. Ophthalmologica 1989;198:124-8.

6. Chee SP, Ang CL. Endogenous Klebsiella endophthalmitis: a case series. Ann Acad Med Singapore 1995;24:473-8.

7. Margo CE, Mames RN, Guy JR. Endogenous Klebsiella endophthalmitis: report of two cases and review of the literature. Ophthalmology 1994;101:1298-301.

8. Chou FF, Kou HK. Endogenous endophthalmitis associated with pyogenic hepatic abscess. J Am Coll Surg 1996;182:33-6.

9. Liu YC, Chang DL, Lin CL. Klebsiella pneumoniae liver abscess associated with septic endophthalmitis. Arch Intern Med $1986 ; 146: 1913-6$.

10. Han SH. Review of hepatic abscess from Klebsiella pneumoniae: an association with diabetes mellitus and septic endophthalmitis. West J Med 1995;162:220-4.

11. Yarng SS, Hsieh CL, Chen TL. Vitrectomy for endogenous Klebsiella pneumoniae endophthalmitis with massive subretinal abscess. Ophthalmic Surg Lasers 1997;28:147-50.

12. Saccente M. Klebsiella pneumoniae liver abscess, endophthalmitis, and meningitis in a man with newly recognized diabetes mellitus. Clin Infect Dis 1999;29:1570-1.

13. Linstrom ST, Healey PR, Chen SC. Metastatic septic endophthalmitis complicating pyogenic liver abscess caused by Klebsiella pneumoniae. Aust N Z Med 1997;27:77-8.

14. Muller JP, Destee A, Guilbert F, Verier A, Warot P. 'Spontaneous' Klebsiella pneumoniae septicemia with ocular and meningeal localizations [letter]. Arch Ophthalmol 1985;103:1109.

15. Liao HR, Lee HW, Leu HS, Lin BJ, Juang CJ. Endogenous Klebsiella pneumoniae endopthalmitis in diabetic patients. Can J Ophthalmol 1992;27:143-7.

16. Cheng DL, Liu YC, Yen MY, Liu CY, Wang RS. Septic metastatic lesions of pyogenic liver abscess: their association with Klebsiella pneumoniae bacteremia in diabetic patients. Arch Intern Med 1991;151:1557-9.

17. Puliafito CA, Baker AS, Haaf J, Foster CS. Infectious endophthalmitis: review of 36 cases. Ophthalmology 1982;89:921-9. 
18. Diamond JG. Intraocular management of endophthalmitis: a systematic approach. Arch Ophthalmol 1981;99:95-9.

19. Forster PK, Abbott RL, Gelender H. Management of infectious endophthalmitis. Ophthalmology 1980;87:313-9.

20. Farber BP, Weinbaum DL, Dummer S. Metastatic bacterial endophthalmitis. Arch Intern Med 1985;145:62-4.

21. Sanford JP. Guide to antimicrobial therapy. West Bethesda, MD: Antimicrobial Therapy Inc., 1991:39.
22. Campochiaro PA, Conway BP. Aminoglycoside toxicity: a survey of retinal specialists. Implications for ocular use. Arch Ophthalmol 1991;109:946-50.

23. Endophthalmitis Vitrectomy Study Group. Results of the endophthalmitis vitrectomy study: a randomized trial of immediate vitrectomy and of intravenous antibiotics for the treatment of postoperative bacterial endophthalmitis. Arch Ophthalmol 1995;113:1479-96. 